\title{
miR-139-5p affects cell proliferation, migration and adipogenesis by targeting insulin-like growth factor 1 receptor in hemangioma stem cells
}

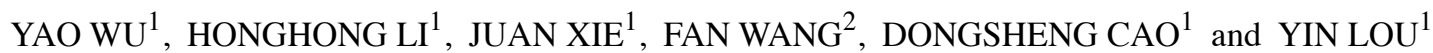 \\ ${ }^{1}$ Department of Plastic Surgery, The Second Affiliated Hospital of Anhui Medical University, Hefei, Anhui 230601; \\ ${ }^{2}$ Department of Plastic Surgery, The Fourth Affiliated Hospital of Anhui Medical University, Hefei, Anhui 230012, P.R. China
}

Received September 22, 2019; Accepted December 2, 2019

DOI: $10.3892 /$ ijmm.2019.4430

\begin{abstract}
Infant hemangioma is the most common benign tumor in infancy. The pathological development process of this tumor is separated into the proliferation period, the involution period and the composite period in which a few residual capillary-like vessels grow through the loose fibrofatty tissue. Previous studies have confirmed that insulin-like growth factor 1 (IGF-1) is able to facilitate the cell proliferation of hemangioma stem cells (HemSCs) and the differentiation of HemSCs into adipocytes. Additionally, studies have confirmed that microRNAs (miRs) may serve a crucial function in regulating the IGF-1 receptor (IGF-1R). miR-139-5p often functions as a tumor suppressor. The present study was designed to investigate the mechanism of miR-139-5p in HemSCs. Dual luciferase reporter results verified that IGF-1R is the target gene of miR-139-5p. miR-139-5p overexpression reduced IGF-1R expression, and miR-139-5p inhibition increased IGF-1R expression. Cell Counting Kit-8 and Transwell migration assays demonstrated that miR-139-5p overexpression may target IGF-1R to inhibit the proliferation in addition to the migration of HemSCs. Reverse transcription-quantitative PCR, oil red o staining and western blot analysis confirmed that miR-139-5p overexpression was able to reduce adipogenesis in HemSCs via the IGF-1/IGF-1R pathway. In contrary, miR-139-5p inhibition substantially enhanced the proliferation, migration and adipogenesis of HemSCs. Overall, miR-139-5p is able to affect the IGF-1/IGF-1R pathway by regulating IGF-1R expression, which ultimately affects the proliferation, migration and adipogenesis of HemSCs.
\end{abstract}

Correspondence to: Dr Dongsheng Cao or Dr Yin Lou, Department of Plastic Surgery, The Second Affiliated Hospital of Anhui Medical University, 678 Furong Road, Hefei, Anhui 230601, P.R. China

E-mail: dscao1966@126.com

E-mail: 137322289@qq.com

Key words: microRNA, hemangioma stem cells, proliferation, migration, adipogenesis

\section{Introduction}

Infant hemangioma ( $\mathrm{IH})$ is a common benign vascular lesion in childhood and consists of hyperactive endothelial cells (1). IH usually grows slowly at 2 weeks or 4 weeks following birth and proliferates rapidly within 6-10 months. The growth rate of the tumor slows down at 12-14 months, and the tumor eventually degrades slowly following 5-10 years (1). IH is most commonly located in the head, face and neck, followed by the limbs and trunk (2). Approximately $20 \%$ of complex cases are accompanied by a series of complications, including deformity, visual impairment, bleeding, congestive heart failure and even mortality (3). In previous years, there have been numerous treatment developments, including surgical hemangioma tissue removal and propranolol injection. However, surgical treatment may result in postoperative scarring, and the exact mechanism of propranolol in IH is not yet understood (4). Therefore, it is necessary to identify safer and more effective treatment strategies and their associated mechanisms for the treatment of IH.

At present, it is known that the primary candidates for the cellular sources of IH are hemangioma stem cells (HemSCs) (5). One previous study confirmed that insulin-like growth factor 1 (IGF-1) may facilitate HemSCs proliferation, in addition to HemSCs differentiation into adipocytes, and enhance lipogenesis (6). IGF-1 binds specifically to IGF-1 receptor (IGF-1R) and affects the expression of peroxisome proliferator-activated receptor- $\gamma 2$ (PPAR- $\gamma 2$ ) through the phosphoinositide 3-kinase $(\mathrm{PI} 3 \mathrm{~K}) /$ protein kinase B (AKT) pathway (7). PPAR- $\gamma 2$ is a key factor that directs adipocyte differentiation by controlling the expression of specific differentiation-associated adipocyte genes $(8,9)$. MicroRNAs (miRs) are non-coding, endogenous, single-stranded, short RNAs with lengths of 20-23 nucleotides. miRs may regulate the expression of genes through binding to their complementary sequences, which are in the target mRNA 3'-untranslated regions (3'-UTRs) (10-12). miRs have been recognized for their involvement in tumor development and their potential as prognostic biomarkers (13). For instance, miR-424 inhibits the basic fibroblast growth factor/fibroblast growth factor receptor 1 pathway, thereby suppressing proliferation, tube formation capability and migration in HemSCs (14). In addition, miR-138 inhibits the differentiation 
of human adipose tissue-derived mesenchymal stem cells into adipocytes (15). One previous study also confirmed that miR-139-5p overexpression may inhibit non-small cell lung cancer cell proliferation, migration and invasion by downregulating IGF-1R expression (16). Based on prior results, miR-139-5p may influence HemSCs adipogenesis, migration and proliferation, and IGF-1R may be its target.

The present study examined the effect, expression and mechanism of miR-139-5p in IH. The aim was to provide novel insight into how miR-139-5p may affect HemSCs proliferation and adipogenesis through the IGF-1/IGF-1R pathway. This information may be utilized to identify novel treatments for patients with IH.

\section{Materials and methods}

Tissue specimen collection. A total of 20 samples of IH were collected between January 2018 and July 2019 at the Institute of Plastic Surgery of Second Affiliated Hospital of Anhui Medical University (Anhui, China). Among the 20 cases, male and female infantile skin hemangioma accounted for 8 cases and 12 cases, respectively. Inclusion criteria were as follows: i) Age $\leq 12$ months; ii) specimen confirmed as hemangioma by clinicians and pathologists; iii) hemangioma specimens in the proliferative phase (determined according to the WHO standards); iv) the patient did not receive any other treatment prior to surgery; v) written informed consent was obtained from the legal guardians of the patients. The study was approved by the Ethics Committee of the Second Hospital of Anhui Medical University (approval no. PJ-bb2017-026). Each hemangioma tissue was acquired on a different day, and HemSCs were rapidly isolated and cultured separately until the third generation for subsequent experiments.

Isolation and identification of HemSCs. Proliferating IH tissues removed from the patients were immediately immersed in growth medium [10\% fetal bovine serum (FBS; GE Healthcare Life Sciences), $1 \%$ penicillin-streptomycin (PS; Gibco; Thermo Fisher Scientific, Inc.) and Dulbecco's modified Eagle's medium (DMEM; Beyotime Institute of Biotechnology)] at $4^{\circ} \mathrm{C}$. The following steps were performed on a clean cell bench. First, the fat and skin tissues were removed from the hemangiomas, and the samples were rinsed three times with phosphate-buffered saline (PBS; BasalMedia). The tissues were then fully chopped and digested with $0.2 \%$ collagenase (SERVA Electrophoresis $\mathrm{GmbH}$ ) in a constant temperature bath at $37^{\circ} \mathrm{C}$ for $2 \mathrm{~h}$ and shaken a number of times every half hour until the samples were chylous. The samples were then filtered through a 100-micron cell strainer. The cells expressing CD133 (17) were selected using a magnetic bead technique (Miltenyi Biotec, Inc.). Finally, the cells were cultivated on fibronectin-coated plates in an appropriate amount of the endothelial cell medium (ECM; ScienCell Research Laboratories, Inc.) with $20 \%$ FBS and $1 \%$ PS in a wet incubator with $5 \%$ carbon dioxide at $37^{\circ} \mathrm{C}$.

Cell culture and transfection. A miR-139-5p inhibitor and mimics were created by Nanjing KeyGen Biotech Co., Ltd. The sequences were as follows: miR-139-5p mimics sense, UCUACAGUGCACGUGUCUCCAGU and antisense, ACU
GGAGACACGUGCACUGUAGA; miR-139-5p inhibitor, ACU GGA GAC ACG UGC ACU GUAGA; miR-139-5p mimics negative control (FAM-dN-CTL) sense, UUUGUA CUACACAAAAGUACUG and antisense, CAGUACUUU UGUGUAGUACAAA; and miR-139-5p inhibitor negative control (FAM-N-CTL), CAGUACUUUUGUGUAGUACAA. HemSCs were seeded in 6-well plates (Corning Inc.) at a density of $1 \times 10^{6}$ cells $/ \mathrm{ml}$ per well, and the cell density reached 50-60\% confluence the following day. Prior to transfection, the cells were rinsed twice with PBS prior to transfection, and $2 \mathrm{ml} \mathrm{ECM} \mathrm{containing} \mathrm{10 \%} \mathrm{FBS} \mathrm{was} \mathrm{added} \mathrm{to} \mathrm{each} \mathrm{well.}$ Subsequently, 110 pmol miR-139-5p mimics or inhibitor was diluted in $200 \mu 1$ jetPRIME buffer (Polyplus-transfection SA) and mixed. Then, $4 \mu 1$ jetPRIME reagent (Polyplus-transfection SA) was added and vortexed briefly for $10 \mathrm{sec}$ and cultured for 10-50 min at room temperature. Finally, miR-139-5p mimics or inhibitor were added to the appropriate wells. At $24 \mathrm{~h}$, the medium was replaced with fresh ECM, and a number of groups were treated with $100 \mathrm{ng} / \mathrm{ml}$ IGF-1 (Peprotech, Inc.). The next experiments were performed $48 \mathrm{~h}$ following transfection.

Reverse transcription-quantitative PCR (RT-qPCR). TRIzol reagent (Invitrogen; Thermo Fisher Scientific, Inc.) was utilized to extract whole cellular RNA. cDNA was synthesized through the reverse transcription of $2 \mu \mathrm{g}$ whole RNA utilizing the PrimeScriptTM RT reagent (Takara Biotechnology Co., Ltd.). Reverse transcription was conducted at $37^{\circ} \mathrm{C}$ for $15 \mathrm{~min}$, followed by $85^{\circ} \mathrm{C}$ for $5 \mathrm{sec}$ and $4^{\circ} \mathrm{C}$ for $10 \mathrm{~min}$ for heat inactivation. U6snRNA (Sangon Biotech Co., Ltd.) was utilized as an endogenous control for the quantitative detection of miR-139-5p expression. GAPDH (Sangon Biotech Co., Ltd.) was used as an endogenous control for the quantitative detection of IGF-1R, PPAR- $\gamma$, CCAAT-enhancer-binding protein $(\mathrm{C} / \mathrm{EBP}) \alpha$ and $\mathrm{C} / \mathrm{EBP} \beta$ expression. RT-qPCR was performed using a CFX Connect Real-Time PCR Detection System (Bio-Rad Laboratories, Inc.) according to the manufacturer's protocol. The thermocycling conditions were as follows: Preheating at $95^{\circ} \mathrm{C}$ for $10 \mathrm{~min}$, followed by 40 cycles of $95^{\circ} \mathrm{C}$ for $15 \mathrm{sec}$ and $60^{\circ} \mathrm{C}$ for $1 \mathrm{~min}$, extension at $72^{\circ} \mathrm{C}$ for $35 \mathrm{sec}$, and $4^{\circ} \mathrm{C}$ for preservation. The mRNA relative expression levels were measured using the $2^{-\Delta \Delta \mathrm{Cq}}$ method in triplicate (18). The 20- $\mu 1$ reactions consisted of $1 \mu 1$ sense primer, $1 \mu 1 \mathrm{cDNA}$, $10 \mu 1 \mathrm{SYBR}^{\circledR}$ Premix Ex Taq II (Takara Biotechnology Co., Ltd.), $7 \mu$ I DNase/RNase-free water (Beijing Solarbio Science $\&$ Technology Co., Ltd.) and $1 \mu 1$ anti-sense primer. The qPCR primer sequences are displayed in Table I.

Western blot analysis. Ice-cold protease inhibitor cocktail (TargetMol) and RIPA buffer (Beyotime Institute of Biotechnology) were mixed at a ratio of 1:100. Then, $110 \mu 1$ mixture was added to each well of 6-well plates for total cellular protein extraction. A Bradford Protein Assay kit (Beyotime Institute of Biotechnology) was utilized to determine the protein concentrations. Cell protein extracts (10 $\mu 1 /$ lane) were subjected to SDS-PAGE (Wuhan Servicebio Technology Co., Ltd.) on $10 \%$ polyacrylamide gels at $80 \mathrm{~V}$ for $30 \mathrm{~min}$ and then $120 \mathrm{~V}$ for $1 \mathrm{~h}$. The samples were transferred to Immobilon-P transfer membranes (Merck KGaA) at a constant current of $200 \mathrm{~mA}$. Then, the samples were blocked with Tris-buffered saline with $0.24 \%$ Tween-20 (TBST) containing 5\% non-fat 
Table I. Primer sequences used for reverse transcription-quantitative PCR.

\begin{tabular}{lll}
\hline Gene & \multicolumn{1}{c}{ Sequence $\left(5^{\prime} \rightarrow 3^{\prime}\right)$} & Reverse transcription primer sequence $\left(5^{\prime} \rightarrow 3^{\prime}\right)$ \\
\hline U6 & F: AGAGAAGATTAGCATGGCCCCTG & GTCGTATCCAGTGCAGGGTCCGAGGTAT \\
& R: ATCCAGTGCAGGGTCCGAGG & TCGCACTGGATACGACAAAATA \\
hsa-miR-139-5p & F: CGCGTCTACAGTGCACGTGTC & GTCGTATCCAGTGCAGGGTCCGAGGTA \\
RAPDH & F: GGTGCAGGGTCCGAGGTATT & TTCGCACTGGATACGACACTGGA \\
& R: GGTGGCAGTGATGGCATGGAC & \\
PPAR- $\gamma$ & F: GGCAATTGAATGTCGTGTCTGTGG & \\
C/EBP $\alpha$ & R: CCGCCAACAGCTTCTCCTTCTC & \\
F/EBP $\beta$ & R: GCGAGGAGGATGAAGCCAAGC & \\
& F: TACTACGAGGCGGACTGCTTGG & \\
\hline
\end{tabular}

miR, microRNA; PPAR- $\gamma$, peroxisome proliferator-activated receptor- $\gamma$; C/EBP, CCAAT-enhancer-binding protein.

milk powder for $90 \mathrm{~min}$. The membranes were washed several times with TBST and incubated with primary antibodies overnight at $4^{\circ} \mathrm{C}$. The primary antibodies used were anti- $\beta$-actin (1:1,000; cat. no. AF7018; Affinity Biosciences), anti-IGF-1R (1:500; cat. no. AF6123; Affinity Biosciences), anti-PPAR $\gamma$ (1:500; cat. no. AF6284; Affinity Biosciences), anti-C/EBP $\beta$ (1:500; cat. no. AF7747; Affinity Biosciences) and anti-C/EBP $\alpha$ (1:500; cat. no. AF6333; Affinity Biosciences). The next day, peroxidase-conjugated goat anti-rabbit immunoglobulin $\mathrm{G}$ (cat. no. ZB2301; OriGene Technologies, Inc.) was mixed with TBST at a ratio of 1:10,000 and incubated with the membranes for $1 \mathrm{~h}$ at $37^{\circ} \mathrm{C}$ with slow shaking and then washed several times. Subsequently, the immune blots were visualized with a western blotting detection kit (Advansta Inc.), and the signal was detected using a Protein Imager (Find-dox6; Tanon Science and Technology Co., Ltd.).

Dual luciferase reporter assay. Target gene prediction analysis using miRWalk (http://mirwalk.umm.uni-heidelberg.de) revealed that in the 3'-UTR IGF-1R mRNA sequence, there were potential miR-139-5p binding sites. To determine the binding of miR-139-5p to IGF-1R mRNA, the present study performed a luciferase reporter assay. First, the fragments containing miR-139-5p binding sites were amplified using the following primers: IGF-1R forward, GCCTCGAGCTGGGATAGAAAT GTTTAGGAG and reverse, CGGCGGCCGCGCAACACA AAACAGGACATC (General Biosystems, Inc., Durham, NC, USA). Thus, the wild-type (WT) 3'UTR of IGF-1R was obtained. Then, the wild-type 3'UTR of IGF-1R was used as a template to amplify the mutant-type (Mut) 3'UTR of IGF-1R with a point mutation. The IGF-1R-Mut sequences were as follows: IGF-1R-Mut forward, TTTCAATCACCATAGAAAAGCCCC ATTATGAATT and reverse, GGGGCTTTTCTATGGTGA TTGAAACTGGTAATTT. Next, the segments (IGF-1R-WT and IGF-1R-Mut) were cut by double enzyme digestion and inserted into the psiCHECK ${ }^{\mathrm{TM}}-2$ vector (Shanghai GenePharma Co., Ltd.) at an XhoI site upstream and NotI site downstream with firefly luciferase to construct the corresponding plasmids.
Cells were inoculated in 24-well plates (Corning Incorporated) at a density of $1 \times 10^{5}$ cells/well and then incubated with $5 \%$ carbon dioxide at $37^{\circ} \mathrm{C}$ for $24 \mathrm{~h}$. The plasmids $(500 \mu \mathrm{g} / \mu \mathrm{l}$; mutant and wild-type) were transfected into HemSCs along with miR-139-5p mimics using jetPRIME buffer and jetPRIME reagent (Polyplus-transfection, SA). After $24 \mathrm{~h}$, the luciferase activities were measured utilizing the Dual-Luciferase Reporter Assay System (Promega Corporation) as well as an Infinite M1000 PRO (Tecan Group Ltd.). Renilla luciferase activity was used as the internal control.

Cell Counting Kit-8 (CCK-8) proliferation assay. Logarithmic growth phase-transfected HemSCs were digested and inoculated into 96-well plates (Corning Incorporated) at a density of $1 \times 10^{4}$ cells $/ \mathrm{ml}$. Subsequent to $1,3,5$ and 7 days of cultivation, the cells were treated with CCK-8 reagent (Dojindo Molecular Technologies, Inc.) and cultured at $37^{\circ} \mathrm{C}$ for another $4 \mathrm{~h}$. The absorbance was measured at a wavelength of $490 \mathrm{~nm}$ using a microplate reader (BioTek ELx 800; BioTek Instruments, Inc.) and growth curves were constructed based on the optical density values.

Transwell migration assay. Migration assays were performed using 24-well Transwell chambers (Corning, Inc.). In brief, $600 \mu \mathrm{l}$ ECM containing 30\% FBS was added to each lower chamber. A total of $200 \mu \mathrm{l}$ serum-free DMEM containing $2 \times 10^{4}$ HemSCs that were transfected and treated with IGF-1 were added to the corresponding upper chamber. The cells on the bottom of the chamber were fixed with $4 \%$ paraformaldehyde (Beyotime Institute of Biotechnology) for $30 \mathrm{~min}$ at room temperature subsequent to $24 \mathrm{~h}$ of incubation and stained with a $0.1 \%$ crystal violet (Beijing Solarbio Science \& Technology Co., Ltd.) for $25 \mathrm{~min}$ at room temperature. Subsequent to washing with sterile water three times, the cells were counted under a light microscope (Olympus IX71; Olympus Corporation) at a magnification of $\mathrm{x} 100 \mathrm{using}$ ImageJ software version 1.8.0 (National Institutes of Health). The entire assay was performed three times. 

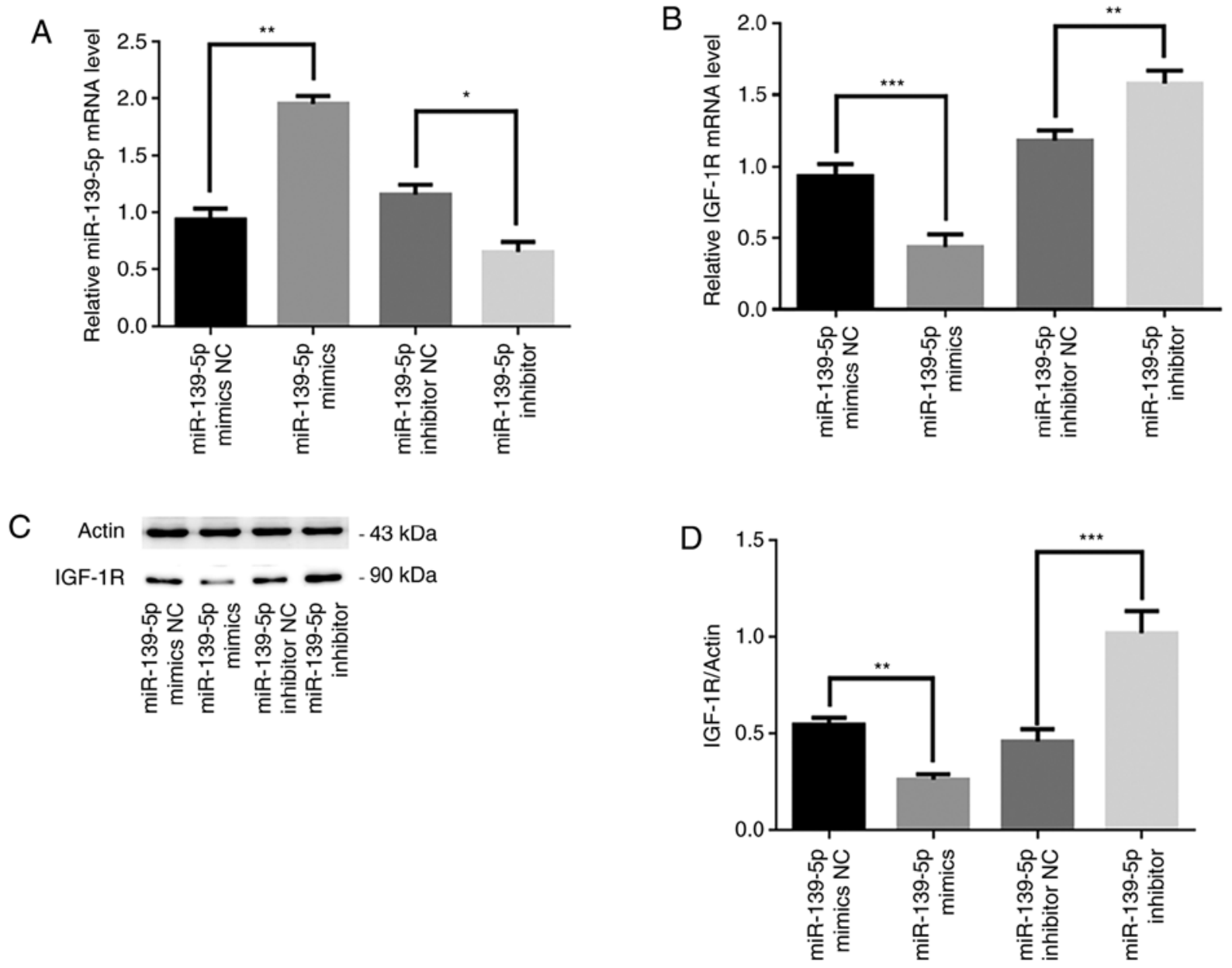

Figure 1. miR-139-5p regulated the expression of IGF-1R in HemSCs. (A) Expression levels of miR-139-5p mRNA in HemSCs transfected with miR-139-5p mimics or inhibitor were assessed using RT-qPCR. (B) Expression levels of IGF-1R mRNA in HemSCs transfected with miR-139-5p mimics or inhibitor were assessed using RT-qPCR. IGF-1R protein expression in HemSCs transfected with miR-139-5p mimics or inhibitor was analyzed by (C) western blot analysis and then (D) quantified, with $\beta$-actin used as the loading control. ${ }^{*} \mathrm{P}<0.05,{ }^{* *} \mathrm{P}<0.01$ and ${ }^{* * * *} \mathrm{P}<0.001$ with comparisons shown by lines. miR, microRNA; IGF-1R, insulin-like growth factor 1 receptor; NC, negative control; HemSCs, hemangioma stem cells; RT-qPCR, reverse transcription-quantitative PCR.

Oil red o-staining. HemSCs were incubated in 6-well plates at a density of $1 \times 10^{6}$ cells $/ \mathrm{ml}$ per well. The different groups were transfected with miR-139-5p mimics or inhibitors, and some of the groups were treated with IGF-1 $(100 \mathrm{ng} / \mathrm{ml})$ on the following day. When cells were over-saturated, the original medium was replaced with adipogenic differentiation media (Cyagen US Inc.), and the cells were incubated at $37^{\circ} \mathrm{C}$ for 10 days. Then the cells were stained with Oil Red O for $30 \mathrm{~min}$ at $37^{\circ} \mathrm{C}$. An Eclipse E800 (Nikon Corporation) microscope was used to photograph the cells.

Statistical analysis. All data are presented as the mean \pm standard deviation ( $\mathrm{n}=3$ for each experiment). Statistical analyses were performed using SPSS 19.0 (IMB Corp.). For multiple groups, one-way analysis of variance followed by Tukey's multiple comparisons test was used to assess the mean values. $\mathrm{P}<0.05$ was considered to indicate a statistically significant difference.

\section{Results}

miR-139-5p regulates the expression of IGF-1R in HemSCs. To investigate whether miR-139-5p was able to alter IGF-1R expression in HemSCs, a pre-experiment was performed.

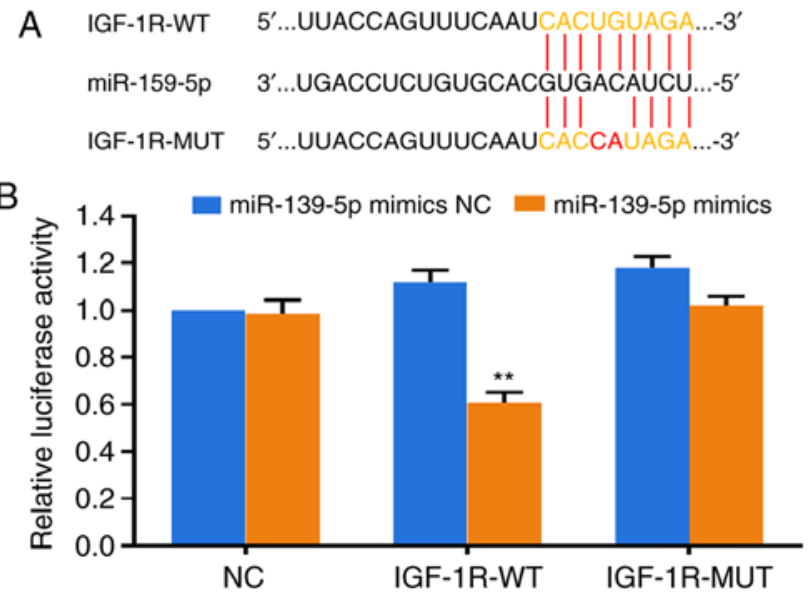

Figure 2. IGF-1R was a target of miR-139-5p. (A) Binding sites of miR-139-5p on the 3'-UTR of IGF-1R (wild-type and mutant) are presented. (B) A luciferase reporter assay revealed that miR-139-5p suppressed the IGF-1R-WT group luciferase activity while it had no effect on the NC group and the IGF-1R-Mut group. ${ }^{* *} \mathrm{P}<0.01$ vs. psiCHECK ${ }^{\mathrm{TM}}-2$ negative control; IGF-1R-WT, partial sequences of the 3'-UTR of IGF-1R binding with miR-139-5p were constructed into psiCHECKTM-2 vector; IGF-1R-MUT, partial sequences of the 3'-UTR of IGF-1R binding with miR-139-5p were mutated and constructed into the psiCHECKTM-2 vector. miR, microRNA; 3'-UTR, 3'-untranslated region; IGF-1R, insulin-like growth factor 1 receptor; $\mathrm{NC}$, negative control. 

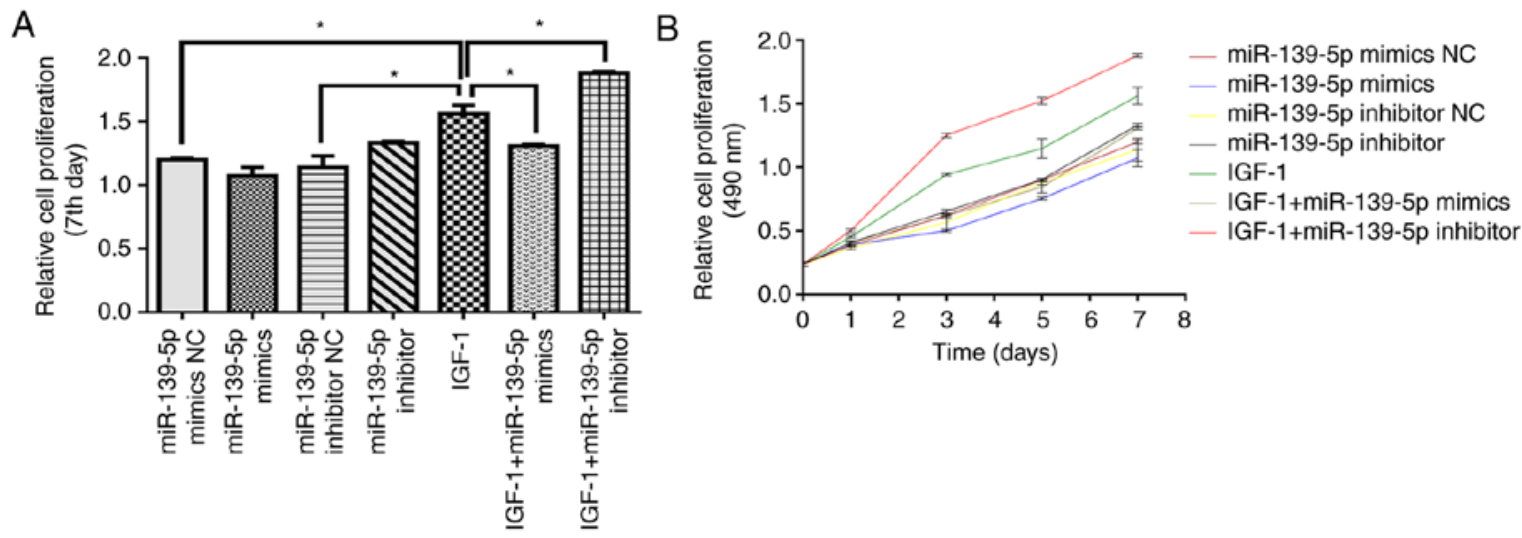

Figure 3. miR-139-5p modulated HemSCs proliferation through IGF-1/IGF-1R (A and B) Cell Counting Kit-8 assay was used to determine the proliferation of HemSCs transfected with miR-139-5p mimics or inhibitor on (A) day 7 or (B) days 1, 3, 5 and 7. "P<0.05. miR, microRNA; IGF-1, insulin-like growth factor 1; IGF-1R, insulin-like growth factor 1 receptor; NC, negative control; HemSCs, hemangioma stem cells.

HemSCs transfected with miR-139-5p mimics as well as inhibitors were used as experimental groups, and HemSCs transfected with miR-139-5p mimics FAM-dN-CTL or miR-139-5p inhibitor FAM-N-CTL were utilized as negative controls. RT-qPCR revealed that miR-139-5p mRNA expression levels following transfection with miR-139-5p mimics or inhibitor were significantly higher and lower, respectively, compared with that in their respective control groups $(\mathrm{P}<0.05$; Fig. 1A). Additionally, IGF-1R mRNA expression levels were significantly lower in miR-139-5p mimics-transfected HemSCs compared with in miR-139-5p mimics FAM-dN-CTL-transfected HemSCs (P<0.001; Fig. 1B). In contrast, the IGF-1R mRNA levels, which were altered using a miR-139-5p inhibitor, were significantly higher compared with that in the miR-139-5p inhibitor FAM-N-CTL group $(\mathrm{P}<0.01$; Fig. 1B). Furthermore, western blot analysis was used to detect IGF-1R protein expression in HemSCs in different groups following transfection, and the same results were revealed. The protein expression levels of IGF-1R were significantly lower in miR-139-5p mimics-transfected HemSCs compared with in miR-139-5p mimics FAM-dN-CTL cells $(\mathrm{P}<0.01)$, whereas the protein expression levels of IGF-1R were significantly higher in miR-139-5p inhibitor-transfected HemSCs compared with in miR-139-5p inhibitor FAM-N-CTL cells $(\mathrm{P}<0.001$; Fig. 1C and D). Therefore, the pre-experiment results revealed that the expression of miR-139-5p may be negatively associated with IGF-1R in HemSCs.

$I G F-1 R$ is a target of miR-139-5p. To further determine the molecular mechanism by which miR-139-5p affected IGF-1R, the target gene software miRWalk was used to predict the potential target genes of miR-139-5p. It was revealed that IGF-1R was a potential target of miR-139-5p on the basis of the presumed target sequences at the 2486-2493 location of the IGF-1R 3'-UTR. To test this prediction, luciferase reporter constructs containing an IGF-1R gene mutant (Mut) or wild-type 3'-UTR were constructed (Fig. 2A). The dual luciferase reporter assay revealed that subsequent to miR-139-5p mimics transfection, luciferase expression was the significantly inhibited in the IGF-1R-WT group compared with the NC group due to IGF-1R binding to miR-139-5p $(\mathrm{P}<0.01)$. The negative control group and the IGF-1R-Mut group did not exhibit altered luciferase expression as they did not bind to miR-139-5p (Fig. 2B). The results indicated that IGF-1R was indeed a miR-139-5p target gene.

miR-139-5p modulates HemSCs proliferation through $I G F-1 / I G F-1 R$. To elucidate whether miR-139-5p may influence HemSCs proliferation in vitro, CCK-8 assays were used to determine the alteration in the proliferation of cells transfected with miR-139-5p inhibitor or mimics. The cell growth curve revealed that IGF-1 significantly facilitated the proliferation of HemSCs compared with the control conditions $(\mathrm{P}<0.05)$. Additionally, miR-139-5p overexpression significantly suppressed HemSCs proliferation compared with IGF-1 alone $(\mathrm{P}<0.05)$, while miR-139-5p inhibition significantly increased HemSCs proliferation ( $\mathrm{P}<0.05$; Fig. $3 \mathrm{~A}$ and $\mathrm{B})$. These results suggested that miR-139-5p modulated IGF-1 binding to IGF-1R by regulating IGF-1R expression and ultimately affected HemSCs proliferation.

miR-139-5p modulates HemSCs migration potentially through the IGF-1/IGF-1R pathway. Transwell migration assays were utilized to verify whether miR-139-5p may affect HemSCs migration. Based on the experimental results, it was revealed that IGF-1 treatment significantly increased the HemSCs migration ability when compared with the control conditions $(\mathrm{P}<0.001)$. In addition, miR-139-5p overexpression significantly suppressed IGF-1-induced cell migration $(\mathrm{P}<0.01)$ and miR-139-5p inhibition significantly increased IGF-1-induced cell migration $(\mathrm{P}<0.01$; Fig. $4 \mathrm{~A}$ and $\mathrm{B})$. Based on these experimental results, it was hypothesized that miR-139-5p may regulate the expression of IGF-1R, thereby affecting the binding of IGF-1 and IGF-1R and further affecting the migration of HemSCs.

miR-139-5p modulates HemSCs differentiation into adipocytes through IGF-1/IGF-1R. In order to further analyze the function of miR-139-5p in the IGF-1/IGF-1R signaling pathway, RT-qPCR, oil red o staining and western blot analysis were performed to examine the effect of miR-139-5p on the adipogenic differentiation of HemSCs. First, it was revealed that IGF-1 treatment stimulated adipogenesis and lipid accumulation in HemSCs, as determined by oil red o 
A

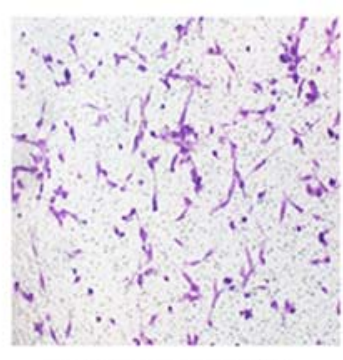

miR-139-5p mimics NC

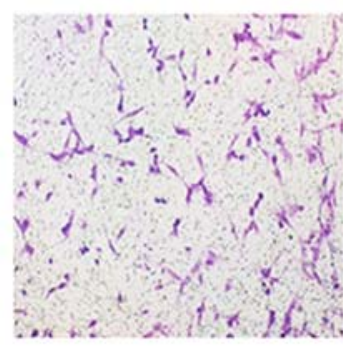

miR-139-5p mimics

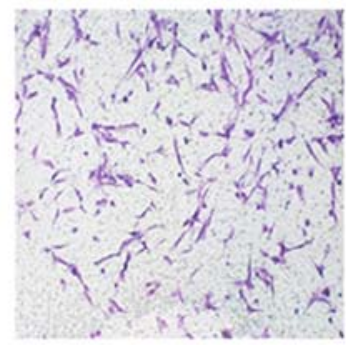

miR-139-5p inhibitor NC

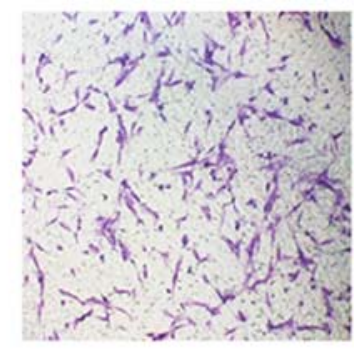

miR-139-5p inhibitor

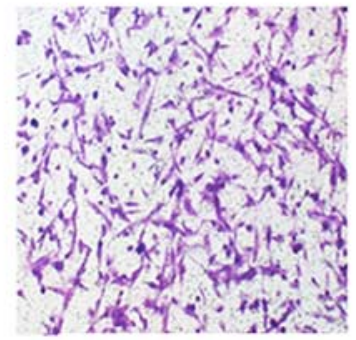

IGF-1

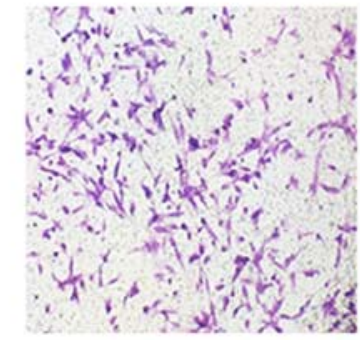

IGF-1+miR-139-5p mimics

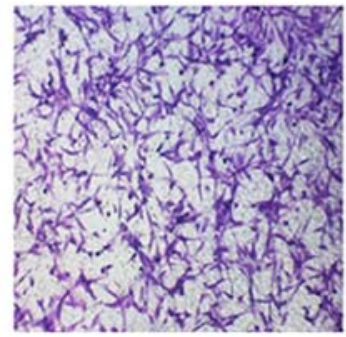

IGF-1+miR-139-5p inhibitor

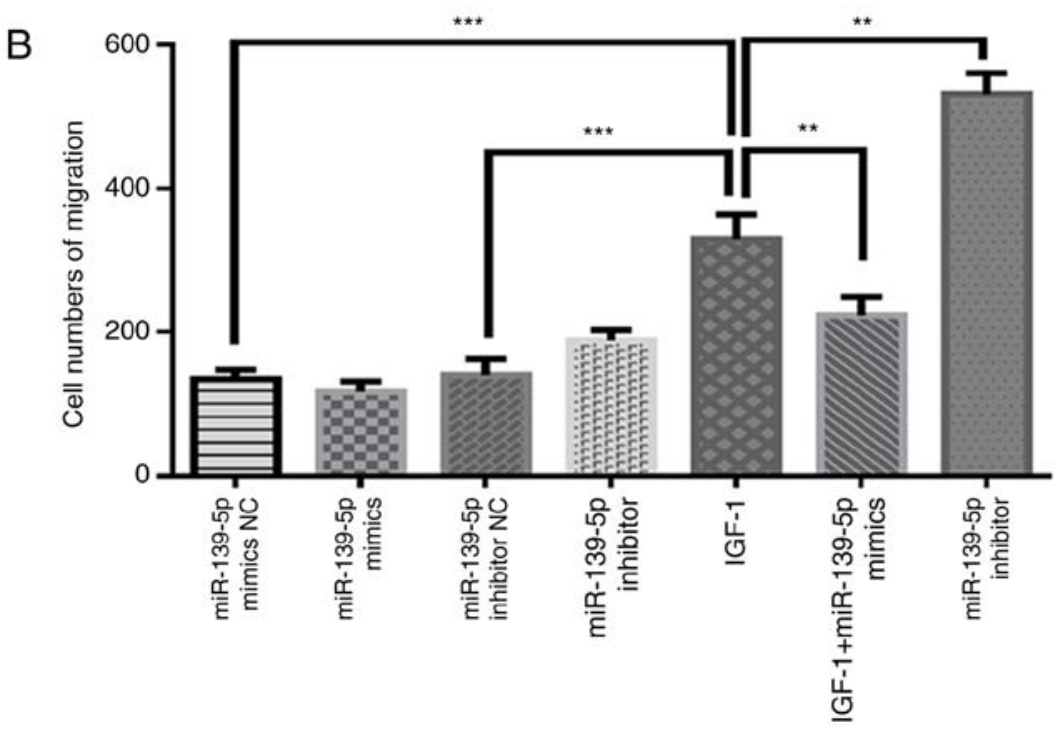

Figure 4. miR-139-5p modulated HemSCs migration through IGF-1/IGF-1R. (A) Transwell migration assays were used to determine the migration capability of HemSCs transfected with miR-139-5p mimics or inhibitor and treated with or without $100 \mathrm{ng} / \mathrm{ml} \mathrm{IGF-1.(B)} \mathrm{Quantified} \mathrm{number} \mathrm{of} \mathrm{migrated} \mathrm{cells.}{ }^{* *} \mathrm{P}<0.01$ and ${ }_{* * * * *} \mathrm{P}<0.001$. miR, microRNA; IGF-1, insulin-like growth factor 1; IGF-1R, insulin-like growth factor 1 receptor; NC, negative control; HemSCs, hemangioma stem cells.

staining. Additionally, miR-139-5p overexpression significantly suppressed IGF-1-induced lipid accumulation $(\mathrm{P}<0.01)$, whereas miR-139-5p inhibition significantly strengthened IGF-1-induced lipid accumulation ( $\mathrm{P}<0.05$; Fig. 5A and B). These results were further verified by western blot analysis in addition to RT-qPCR. These data revealed that IGF-1 treatment significantly facilitated PPAR $\gamma, \mathrm{C} / \mathrm{EBP} \alpha$ and $\mathrm{C} / \mathrm{EBP} \beta$ expression in HemSCs compared with the controls $(\mathrm{P}<0.05)$, and miR-139-5p overexpression significantly reduced the expression of transcription regulators compared with IGF-1 treatment alone $(\mathrm{P}<0.01)$. In contrast, miR-139-5p inhibition significantly increased the expression of these transcription regulators $(\mathrm{P}<0.01$; Fig. 5C-I). Therefore, the present results indicated that miR-139-5p may modulate the differentiation of HemSCs into adipocytes by affecting the IGF-1/IGF-1R signaling pathway.

\section{Discussion}

The cellular elements of IH change constantly throughout the life cycle of growth and regression. The endothelial cells that predominate in the proliferation period progressively decrease during the involution phase. Conversely, adipocytes increase and then ultimately dominate in the involution period (19). However, the mechanisms that are conducive to adipogenesis throughout spontaneous regression are unclear.

A previous study confirmed that IGF-1 is able to promote HemSCs proliferation in addition to adipogenesis (6). The biological effects of IGF-1 were mediated through IGF-1R, a member of the growth factor receptor tyrosine family $(20,21)$. IGF-1R may induce differentiation in certain types of cells, including adipocytes (22), osteoblasts (23) and central nervous system cells (24-26). In previous years, numerous studies have 
A
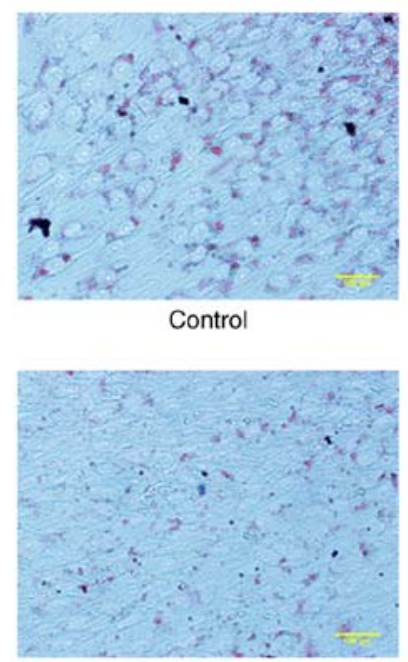

IGF-1+miR-139-5p mimics

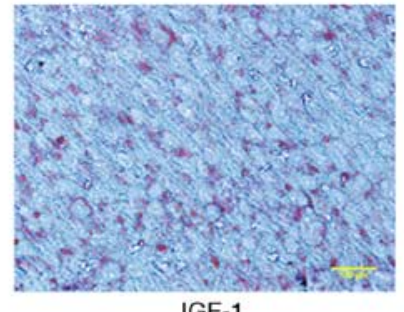

IGF-1

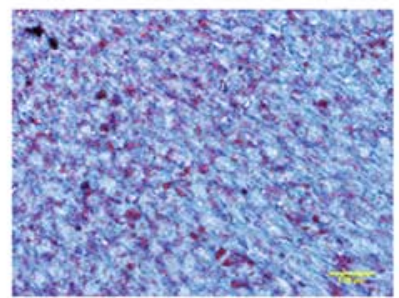

IGF-1+miR-139-5p inhibitor
B
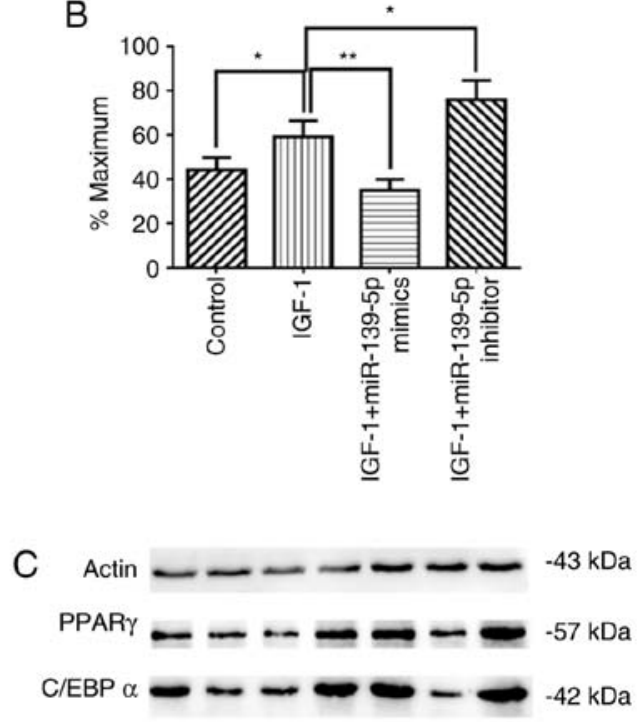

C/EBP $\beta$

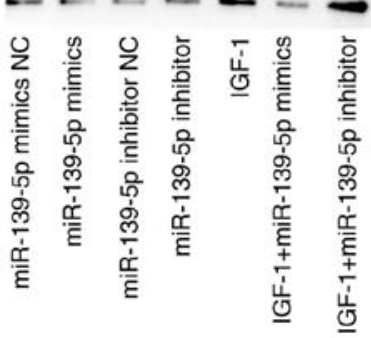

E
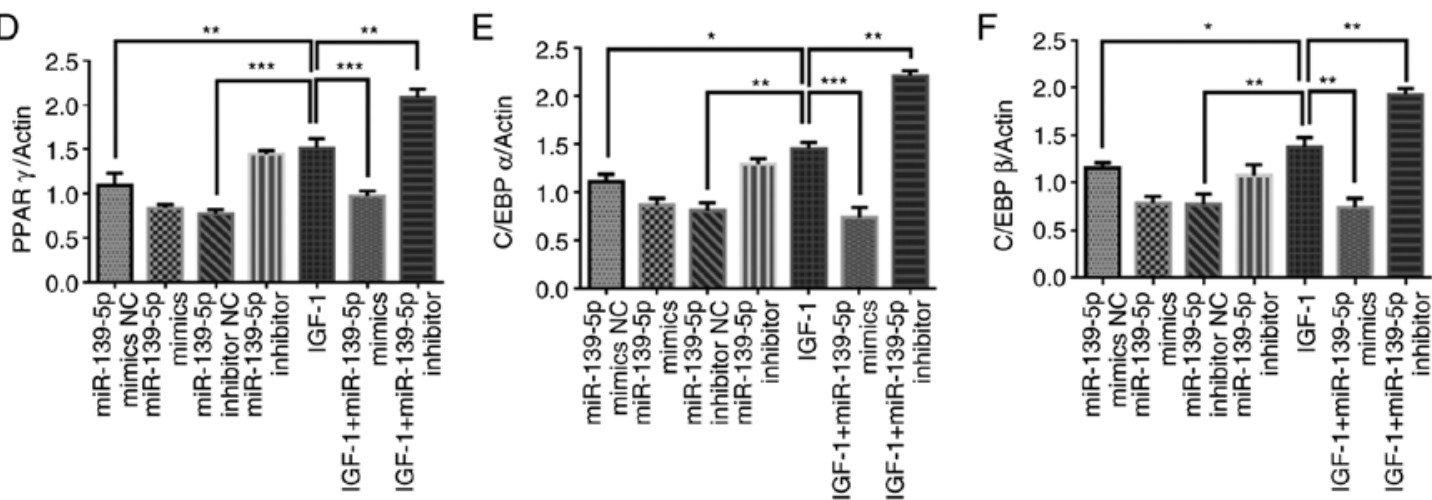

G

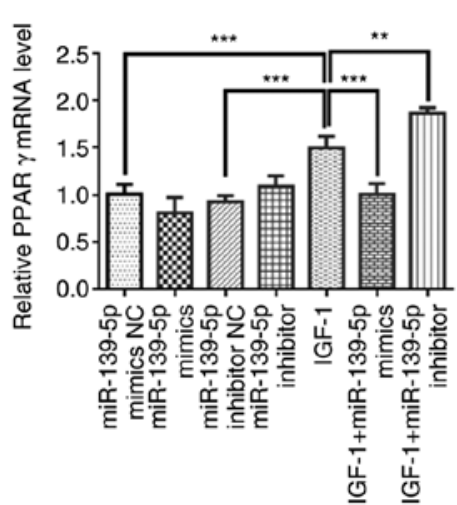

$\mathrm{H}$

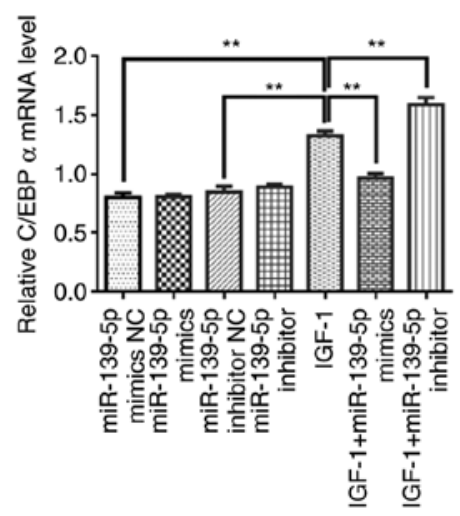

I

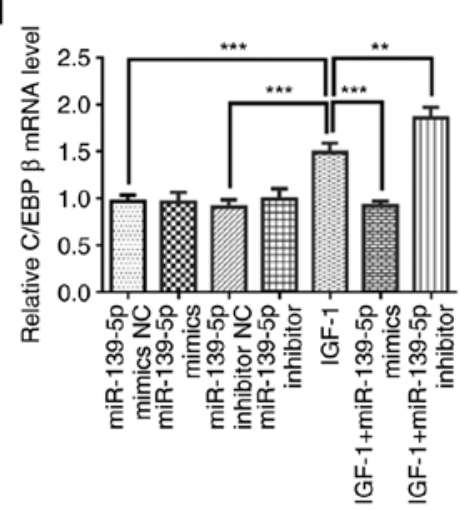

Figure 5. miR-139-5p modulated HemSCs differentiation into adipocytes through IGF-1/IGF-1R. (A) Adipogenic differentiation of HemSCs was determined by oil red o staining to visualize intracellular lipid droplet accumulation. (B) Oil red o-stained cells were quantified using ImageJ software. (C) Western blot analysis demonstrated the expression levels of (D) PPAR- $\gamma$, (E) C/EBP $\alpha$ and (F) C/EBP $\beta$ in HemSCs transfected with miR-139-5p mimics or inhibitor and treated with or without $100 \mathrm{ng} / \mathrm{ml} \mathrm{IGF-1.} \mathrm{(G-I)} \mathrm{Expression} \mathrm{of} \mathrm{(G)} \mathrm{PPAR-} \gamma,(\mathrm{H}) \mathrm{C} / \mathrm{EBP} \alpha$ and (I) C/EBP $\beta$ mRNA in HemSCs transfected with miR-139-5p mimics or inhibitor and treated with or without $100 \mathrm{ng} / \mathrm{ml} \mathrm{IGF-1} \mathrm{were} \mathrm{assessed} \mathrm{using} \mathrm{reverse} \mathrm{transcription-quantitative} \mathrm{PCR}$. ${ }^{*} \mathrm{P}<0.05,{ }^{* *} \mathrm{P}<0.01$ and ${ }^{* * *} \mathrm{P}<0.001$. miR, microRNA; IGF-1, insulin-like growth factor 1; IGF-1R, insulin-like growth factor 1 receptor; NC, negative control; HemSCs, hemangioma stem cells; PPAR- $\gamma$, peroxisome proliferator-activated receptor- $\gamma$; C/EBP, CCAAT-enhancer-binding protein. 
revealed that miRs may serve a crucial function in regulating IGF-1R. For instance, miR-335 induces migration by targeting IGF-1R (27), whereas miR-505 suppresses hepatocellular carcinoma cell growth by targeting IGF-1R (28). On the basis of these reports, miR-139-5p was revealed to affect the development of various tumor types through IGF-1R. For instance, Cui et al (29) proved that miR-139 suppresses the generation and proliferation of $\beta$-casein by targeting IGF-1R in bovine mammary epithelial cells. Nam et al (30) confirmed that the overexpression of miR-139 may inhibit IGF-1R and ultimately inhibit the proliferation and migration of prostate cancer cells through the downstream effects of the PI3K/AKT pathway. However, to the best of our knowledge, there is no existing research on how miR-139-5p may affect the proliferation, differentiation and migration of HemSCs. The present study initially revealed that the expression of miR-139-5p may be negatively associated with IGF-1R in HemSCs via a pre-experiment. This may suggest that miR-139-5p is involved in the migration and proliferation of HemSCs and that IGF-1R may be its target. Therefore, the present study was conducted to further investigate the function and specific mechanism of miR-139-5p in HemSCs. First, the present study validated that IGF-1R was a miR-139-5p target using a dual luciferase reporter assay. Next, $\mathrm{CCK}-8$ and Transwell assays revealed that miR-139-5p was able to affect the migration and proliferation of HemSCs by modulating the IGF-1/IGF-1R pathway.

In addition, one previous study has revealed that the transcription regulator PPAR $\gamma$ and C/EBP family members serve important functions in the development of adipose cells (8). Yuan et al (31) confirmed that PPAR- $\gamma 2$ gene overexpression may upregulate adipogenic-associated genes and may strengthen and speed up the differentiation of HemSCs into adipocytes. Another study confirmed that IGF-1 is able to participate in the regulation of PPAR $\gamma$ and C/EBP, so IGF-1 serves a crucial function in preadipocyte growth in addition to differentiation (32). Furthermore, Maoa et al (33) revealed that the deletion of miR-139-5p promoted the occurrence and development of colute carrier family 25 member 20 through the PI3K/AKT and Wnt pathway mediated by IGF-1R. Based on these and the present experimental results, the present study examined whether miR-139-5p may affect the adipogenesis of HemSCs through the IGF-1/IGF-1R pathway. It was confirmed that IGF-1 may stimulate adipogenesis and lipid accumulation in HemSCs via oil red o staining. miR-139-5p affected the binding of IGF-1R to IGF-1 by regulating the expression level of IGF-1R, which affected the differentiation of HemSCs into adipocytes. Furthermore, the present study detected PPAR $\gamma$, $\mathrm{C} / \mathrm{EBP} \alpha$ and $\mathrm{C} / \mathrm{EBP} \beta$ expression through western blot analysis in addition to RT-qPCR, further verifying the results of previous experiments. It should also be noted that PI3K/AKT is a crucial signaling cascade for the mediation of the IGF-1R signal (34). Numerous studies have revealed the crucial function of the PI3K/AKT signaling cascade during adipogenesis (35-39). For example, the PI3K/AKT signaling pathway mediated by insulin may result in excessive lipids in adipose tissue, so it serves a crucial function in the adipose cells of patients with obesity (40). A previous study revealed that IGF-1 upregulated the phosphorylation of AKT through the IGF-1R-PI3K signaling pathway, which ultimately induced the differentiation of HemSCs into adipocytes (6). In addition, a study performed by Mi et al (41) proved that miR-139-5p inhibited the differentiation of 3T3-L1 preadipocytes by regulating the insulin receptor substrate 1/PI3K/AKT signaling pathways. Based on the results of previous studies and the present experimental results, it was hypothesized that miR-139-5p may affect the adipogenesis of HemSCs through the IGF-1R-PI3K signaling pathway. This hypothesis was not verified, but this will be the direction of future research. In fact, the ideal treatment for IH is to inhibit angiogenesis and promote adipogenesis. If the present study is able to further verify whether miR-139-5p may affect $\mathrm{IH}$ angiogenesis, it will better verify that miR-139-5p serves an important function in the treatment mechanism of IH.

To the best of our knowledge, this is the first study on the function of miR-139-5p and its potential mechanism in HemSCs. Although the present study had certain limitations, there are no relevant studies on the effect of miR-139-5p on the $\mathrm{PI} 3 \mathrm{~K} / \mathrm{AKT}$ signaling pathway. However, the present in vitro experiments indicated that miR-139-5p may affect the migration, proliferation and adipogenesis of HemSCs through the IGF-1/IGF-1R pathway by regulating IGF-1R expression. These data lay the foundation for the following experiments in vivo. The current treatments for $\mathrm{IH}$ are limited, and miR-139-5p may be a novel potential therapeutic target for IH.

\section{Acknowledgements}

Not applicable.

\section{Funding}

The present study was funded by the Natural Science and Technology Fund Project of Anhui Province (grant no. $1808085 \mathrm{MH} 282)$.

\section{Availability of data and materials}

The datasets used and/or analyzed during the present study are available from the corresponding author on reasonable request.

\section{Authors' contributions}

DC and YL designed the experiments. YW performed the experiments and wrote the manuscript. HL, JX and FW analyzed the experimental data. All authors read and approved the final manuscript.

\section{Ethics approval and consent to participate}

The study was ethically approved by the Ethics Committee of the Second Hospital of Anhui Medical University (approval no. PJ-bb2017-026). Written informed consent was obtained from the guardians of the patients.

\section{Patient consent for publication}

Not applicable.

\section{Competing interests}

The authors declare that they have no competing interests. 


\section{References}

1. Boye E, Jinnin M and Olsen BR: Infantile hemangioma: Challenges, new insights, and therapeutic promise. J Craniofac Surg 20 (Suppl 1): S678-S684, 2009.

2. Haggstrom AN, Drolet BA, Baselga E, Chamlin SL, Garzon MC Horii KA, Lucky AW, Mancini AJ, Metry DW, Newell B, et al: Prospective study of infantile hemangiomas: Clinical characteristics predicting complications and treatment. Pediatrics 118 882-887, 2006.

3. Zhao F, Yang X, Xu G, Bi J, Lv R and Huo R: Propranolol suppresses HUVEC viability, migration, VEGF expression, and promotes apoptosis by downregulation of miR-4295. J Cell Biochem 120: 6614-6623, 2019.

4. Zhang K, Wang F, Huang J, Lou Y, Xie J, Li H, Cao D and Huang X: Insulin-like growth factor 2 promotes the adipogenesis of hemangioma-derived stem cells. Exp Ther Med 17: 1663-1669, 2019.

5. Khan ZA, Boscolo E, Picard A, Psutka S, Melero-Martin JM, Bartch TC, Mulliken JB and Bischoff J: Multipotential stem cells recapitulate human infantile hemangioma in immunodeficient mice. J Clin Invest 118: 2592-2599, 2008.

6. Wang F, Li H, Lou Y, Xie J, Cao D and Huang X: Insulinlike growth factor I promotes adipogenesis in hemangioma stem cells from infantile hemangiomas. Mol Med Rep 19: 2825-2830, 2019

7. Chen Q, Shou P, Zheng C, Jiang M, Cao G, Yang Q, Cao J, Xie N, Velletri T, Zhang X, et al: Fate decision of mesenchymal stem cells: Adipocytes or osteoblasts? Cell Death Differ 23: 1128-1139, 2016.

8. Tontonoz P, Hu E and Spiegelman BM: Regulation of adipocyte gene expression and differentiation by peroxisome proliferator activated receptor gamma. Curr Opin Genet Dev 5: 571-576, 1995

9. Zhao P, Deng Y, Gu P, Wang Y, Zhou H, Hu Y, Chen P and Fan X: Insulin-like growth factor 1 promotes the proliferation and adipogenesis of orbital adipose-derived stromal cells in thyroid-associated ophthalmopathy. Exp Eye Res 107: 65-73, 2013.

10. He L and Hannon GJ: MicroRNAs: Small RNAs with a big role in gene regulation. Nat Rev Genet 5: 522-531, 2004.

11. Kasinski AL and Slack FJ: Epigenetics and genetics. MicroRNAs en route to the clinic: Progress in validating and targeting microRNAs for cancer therapy. Nat Rev Cancer 11: 849-864, 2011.

12. Treiber T, Treiber N and Meister G: Regulation of microRNA biogenesis and function. Thromb Haemost 107: 605-610, 2012.

13. Ye Y, Song Y, Zhuang J, Wang G, Ni J, Zhang S and Xia W: MicroRNA-302a-3p suppresses hepatocellular carcinoma progression by inhibiting proliferation and invasion. Onco Targets Ther 11: 8175-8184, 2018.

14. Yang L, Dai J, Li F, Cheng H, Yan D and Ruan Q: The expression and function of miR-424 in infantile skin hemangioma and its mechanism. Sci Rep 7: 11846, 2017.

15. Yang Z, Bian C, Zhou H, Huang S, Wang S, Liao L and Zhao RC: MicroRNA hsa-miR-138 inhibits adipogenic differentiation of human adipose tissue-derived mesenchymal stem cells through adenovirus EID-1. Stem Cells Dev 20: 259-267, 2011.

16. Xu W, Hang M, Yuan C, Wu F, Chen S, Xue K: MicroRNA-139-5p inhibits cell proliferation and invasion by targeting insulin-like growth factor 1 receptor in human non-small cell lung cancer. Int J Clin Exp Pathol 8: 3864-3870, 2015

17. Yuan SM, Guo Y,Zhou XJ, Shen WM and Chen HN: PDGFR- $\beta(+)$ perivascular cells from infantile hemangioma display the features of mesenchymal stem cells and show stronger adipogenic potential in vitro and in vivo. Int J Clin Exp Patho 7: 2861-2870, 2014.

18. Livak KJ and Schmittgen TD: Analysis of relative gene expression data using real-time quantitative PCR and the 2(-Delta DeltaC(T)) method. Methods 25: 402-408, 2001.

19. Yu Y, Fuhr J, Boye E, Gyorffy S, Soker S, Atala A, Mulliken JB and Bischoff $\mathrm{J}$ : Mesenchymal stem cells and adipogenesis in hemangioma involution. Stem Cells 24: 1605-1612, 2006.

20. Boney CM, Gruppuso PA, Faris RA and Frackelton AR Jr: The critical role of Shc in insulin-like growth factor-I-mediated mitogenesis and differentiation in 3T3-L1 preadipocytes. Mol Endocrinol 14: 805-813, 2000.

21. Boney CM, Smith RM and Gruppuso PA: Modulation of insulin-like growth factor I mitogenic signaling in 3T3-L1 preadipocyte differentiation. Endocrinology 139: 1638-1644, 1998.

22. Smith PJ, Wise LS, Berkowitz R, Wan C and Rubin CS: Insulin-like growth factor-I is an essential regulator of the differentiation of 3T3-L1 adipocytes. J Biol Chem 263: 9402-9408, 1988.
23. Schmid C, Steiner T and Froesch ER: Insulin-like growth factor I supports differentiation of cultured osteoblast-like cells. FEBS Lett 173: 48-52, 1984.

24. Mcmorris FA, Smith TM, Desalvo S and Furlanetto RW: Insulin-like growth factor I/somatomedin C: A potent inducer of oligodendrocyte development. Proc Natl Acad Sci USA 83: 822-826, 1986

25. Mill JF, Chao MV and Ishii DN: Insulin, insulin-like growth factor II, and nerve growth factor effects on tubulin mRNA levels and neurite formation. Proc Natl Acad Sci USA 82: 7126-7130, 1985.

26. Recio-Pinto E, Lang FF and Ishii DN: Insulin and insulin-like growth factor II permit nerve growth factor binding and the neurite formation response in cultured human neuroblastoma cells. Brain Res 81: 2562-2566, 1984.

27. Qi J, Shi LY, Wu Y, Shen XJ, Yuan J, Jin CJ, Cong H and Ju SQ: Epigenetic silencing of miR-335 induces migration by targeting insulin-like growth factor-1 receptor in multiple myeloma. Leuk Lymphoma: 1-11, Jun 13, 2019 (Epub ahead of print).

28. Ren L, Yao Y, Wang Y and Wang S: MiR-505 suppressed the growth of hepatocellular carcinoma cells via targeting IGF-1R. Biosci Rep 39: pii: BSR20182442, 2019.

29. Cui Y, Sun X, Jin L, Yu G, Li Q, Gao X, Ao J and Wang C: MiR-139 suppresses $\beta$-casein synthesis and proliferation in bovine mammary epithelial cells by targeting the GHR and IGF1R signaling pathways. BMC Vet Res 13: 350, 2017.

30. Nam RK, Benatar T, Wallis CJD, Kobylecky E, Amemiya Y, Sherman C and Seth A: MicroRNA-139 is a predictor of prostate cancer recurrence and inhibits growth and migration of prostate cancer cells through cell cycle arrest and targeting IGF1R and AXL. Prostate 79: 1422-1438, 2019.

31. Yuan SM, Guo Y, Wang Q, Xu Y, Wang M, Chen HN and Shen WM: Over-expression of PPAR- $\gamma 2$ gene enhances the adipogenic differentiation of hemangioma-derived mesenchymal stem cells in vitro and in vivo. Oncotarget 8: 115817-115828, 2017.

32. Holly J, Sabin M, Perks C and Shield J: Adipogenesis and IGF-1. Metab Syndr Relat Disord 4: 43-50, 2006.

33. Maoa R, Zou F, Yang L, Lin S, Li Y, Ma M, Yin P, Liang X and Liu J: The loss of MiR-139-5p promotes colitis-associated tumorigenesis by mediating PI3K/AKT/Wnt signaling. Int $\mathrm{J}$ Biochem Cell Biol 69: 153-161, 2015.

34. Xu J and Liao K: Protein kinase B/AKT 1 plays a pivotal role in insulin-like growth factor-1 receptor signaling induced 3T3-L1 adipocyte differentiation. J Biol Chem 279: 35914-35922, 2004.

35. Gagnon A, Chen CS and Sorisky A: Activation of protein kinase $\mathrm{B}$ and induction of adipogenesis by insulin in 3T3-L1 preadipocytes: Contribution of phosphoinositide-3,4,5-trisphosphate versus phosphoinositide-3,4-bisphosphate. Diabetes 48: 691-698, 1999.

36. Kohn AD, Summers SA, Birnbaum MJ and Roth RA: Expression of a constitutively active Akt Ser/Thr kinase in 3T3-L1 adipocytes stimulates glucose uptake and glucose transporter 4 translocation. J Biol Chem 271: 31372-31378, 1996.

37. Magun R, Burgering BM, Coffer PJ, Pardasani D, Lin Y, Chabot J and Sorisky A: Expression of a constitutively activated form of protein kinase B (c-Akt) in 3T3-L1 preadipose cells causes spontaneous differentiation. Endocrinology 137: 3590-3593, 1996.

38. Peng XD, Xu PZ, Chen ML, Hahn-Windgassen A, Skeen J, Jacobs J, Sundararajan D, Chen WS, Crawford SE, Coleman KG and Hay N: Dwarfism, impaired skin development, skeletal muscle atrophy, delayed bone development, and impeded adipogenesis in mice lacking Akt1 and Akt2. Gene Dev 17: 1352-1365, 2003.

39. Tomiyama K, Nakata H, Sasa H, Arimura S, Nishio E and Watanabe Y: Wortmannin, a specific phosphatidylinositol 3-kinase inhibitor, inhibits adipocytic differentiation of 3T3-L1 cells. Biochem Bioph Res Commun 212: 263-269, 1995.

40. Cai R, Tang G, Zhang Q, Yong W, Zhang W, Xiao J, Wei C, He C, Yang G and Pang W: A novel lnc-RNA, named lnc-ORA, is identified by RNA-seq analysis, and its knockdown inhibits adipogenesis by regulating the PI3K/AKT/mTOR signaling pathway. Cells 8: pii: E477, 2019.

41. Mi L, Chen Y, Zheng X, Li Y, Zhang Q, Mo D and Yang G: MicroRNA-139-5p suppresses 3T3-L1 preadipocyte differentiation through Notch and IRS1/PI3K/Akt insulin signaling pathways. J Cell Biochem 116: 1195-1204, 2015.

This work is licensed under a Creative Commons Attribution-NonCommercial 4.0 International (CC BY-NC 4.0) License. 